\title{
Delayed re-laparotomy after total hysterectomy
}

\author{
Paridhi Bhatnagar*, Erika Desai, Uday Patel, Bakul Leuva
}

\begin{abstract}
Department of Obstetrics \& Gynecology, SBKS Medical Institute and Research Centre, Pipariya, Waghodia,
\end{abstract} Vadodara, Gujarat, India

Received: 28 January 2013

Accepted: 30 January 2013

*Correspondence:

Dr. Paridhi Bhatnagar

E-mail: drparidhibhatnagar1509@gmail.com

\begin{abstract}
Background: Since beginning it's a dilemma whether to remove or preserve the ovaries. In the present study an attempt is made to understand this phenomenon and to have some direction for removal of ovaries. Preservation of the ovaries at the time of hysterectomy does not seem to compromise patient care. Impaired function or failure of the retained ovaries, however, is not uncommon; close post-treatment surveillance is therefore important in terms not only of recurrent disease but of function of the ovaries as well.

Methods: This study was done on 37 patients in duration of 3 years from June 2009 to May 2012. It is a retrospective statistical hospital based study of re-laparotomy done in post hysterectomised patients.

Results: The most common pathology in these patients was a simple ovarian cyst (45.95\%), followed by endometriotic cyst $(21.62 \%)$, mucinous adenoma (8.10\%), serous cyst adenoma $(5.40 \%)$, serous cyst adenocarcinoma $(2.70 \%)$ and poorly differentiated adenocarcinoma $(2.70 \%)$.

Conclusions: Emergence of pelvic mass after hysterectomy poses diagnostic and therapeutic challenge to gynecologists. In future, as the patients become more aware and the clinicians more enlightened on the long term benefits and risks of hormone replacement therapy, decisions might be easier for the patients and the clinicians alike.
\end{abstract}

Keywords: Adenocarcinoma, Relaparotomy, Hysterectomy

\section{INTRODUCTION}

Since beginning it's a dilemma whether to remove or preserve the ovaries. But when the patient comes back after some related symptoms it is a very difficult situation for the surgeon who has operated. In the United States, $78 \%$ of women 45 to 64 years old and $55 \%$ of women overall undergo bilateral oophorectomy at the time of hysterectomy. ${ }^{1}$ These percentages mean that almost 300,000 women undergo bilateral oophorectomy each year. ${ }^{1}$ Hysterectomy alone can sometimes lead to early ovarian failure, but this phenomenon is infrequent. A prospective study of pre- menopausal women found that, after 5 years of follow-up, $20 \%$ of women who underwent simple hysterectomy reached menopause, compared with $7 \%$ of matched women who did not undergo hysterectomy. ${ }^{2}$ The symptoms for which the patient is likely to come back may vary from very minor pain in abdomen, urinary problem to large ovarian cysts and rarely symptoms of a malignant growth. In the present study an attempt is made to understand this phenomenon and to have some direction for removal of ovaries. Preservation of the ovaries at the time of hysterectomy does not seem to compromise patient care. Impaired function or failure of the retained ovaries, however, is not uncommon; close post-treatment surveillance is therefore important in terms not only of recurrent disease but of function of the ovaries as well.

\section{Aims of the study}

1. To know the incidence of relaparotomy for ovarian mass in post- hysterectomy patients.

2. To study the indications of relaparotomy

3. To study the time interval between hysterectomy and relaparotomy

\section{METHODS}

This is a retrospective, statistical, hospital based study of re-laparotomy done in post hysterectomised patients who came to Dhiraj General Hospital in the Department of Obstetrics and Gynecology. 
The study was done on 37 patients in duration of 3 years from June 2009 to May 2012.

Inclusion criteria: (i) Age $>35$ years at the time of hysterectomy, (ii) Total abdominal hysterectomy done for benign diseases and either one or both ovaries are left behind, (iii) Relaparotomy done in patients with clinical diagnosis of adnexal mass.

The study comprises of 37 patients who underwent laparotomy for adnexal mass 1-9 years following hysterectomy. After confirming the diagnosis, ovaries were removed and sent for histopathological examination.

\section{RESULTS}

The age at hysterectomy is shown in table 1. It was observed that in most of the patients the time interval between hysterectomy and laparotomy was 1-6 years (Table 2). Another interesting observation that we made was regarding the reason for symptoms in comparison with time interval.

Table 1: Age at hysterectomy.

\begin{tabular}{|lcc|}
\hline Age of the patient & No of cases & Percentage $(\%)$ \\
\hline$<40$ years & 17 & 45.95 \\
\hline $40-45$ years & 18 & 48.65 \\
\hline$>45$ years & 02 & 5.41 \\
\hline
\end{tabular}

Table 2: Interval between hysterectomy and laparotomy.

\begin{tabular}{|ccc|}
\hline Time interval & No. of cases & Percentage $(\%)$ \\
\hline 1-3 years & 17 & 45.95 \\
\hline 3-6 years & 16 & 43.24 \\
\hline 6-9 years & 04 & 10.81 \\
\hline
\end{tabular}

All the 3 patients with intra peritoneal adhesions had the time interval of hysterectomy between 1-3 years. In patients with time interval of 3-6 years, $64 \%$ had bilateral ovarian mass whereas in patients with time interval of 6-9 years, $71.20 \%$ had unilateral ovarian mass (Table 3). Amongst these, $21(56.76 \%)$ women underwent total abdominal hysterectomy, 7(18.92\%) women underwent total abdominal hysterectomy with unilateral salpingooophorectomy whereas $9(24.32 \%)$ were operated vaginally as shown in the table 4 .

Table 3: Correlation between time interval and intraoperative findings.

\begin{tabular}{|ll|}
\hline Time interval & $\begin{array}{l}\text { Most common } \\
\text { intraoperative finding }\end{array}$ \\
\hline 1-3 years & Adhesions \\
\hline 3-6 years & Bilateral ovarian masses \\
\hline 6-9 years & Unilateral ovarian masses \\
\hline
\end{tabular}

Table 4: Types of hysterectomy.

\begin{tabular}{|lll|}
\hline Type of operation & No. of cases & $\begin{array}{l}\text { Percentage } \\
(\%)\end{array}$ \\
\hline TAH & 21 & 56.76 \\
\hline $\begin{array}{l}\text { TAH with unilateral } \\
\text { salpingo-oophorectomy }\end{array}$ & 07 & 18.92 \\
\hline Vaginal hysterectomy & 9 & 24.32 \\
\hline
\end{tabular}

In this study of 37 patients the most common indication for hysterectomy was dysfunctional uterine bleeding (32.43\%), followed by prolapse uterus (24.32\%), PID (21.62\%), fibroid (13.51\%), adenomyosis $(8.10 \%)$ (Table 5).

Table 5: Indications for hysterectomy.

\begin{tabular}{|lll|}
\hline Indications & No. of cases & Percentage (\%) \\
\hline DUB & 12 & 32.43 \\
\hline Prolapse & 09 & 24.32 \\
\hline PID & 08 & 21.62 \\
\hline Fibroid & 05 & 13.51 \\
\hline Adenomyosis & 03 & 8.10 \\
\hline
\end{tabular}

The most common symptom with which these patients presented was pain in abdomen $(56.76 \%)$, followed by vague symptoms like abdominal distention, GI symptoms, burning micturition, and pelvic heaviness. In $10.81 \%$ patients, there were no symptoms and the presence of an ovarian mass was an incidental finding on USG (Table 6).

Table 6: Symptoms of patients.

\begin{tabular}{|lll|}
\hline Symptoms & $\begin{array}{l}\text { No. of } \\
\text { patients }\end{array}$ & Percentage (\%) \\
\hline Pain in abdomen & 21 & 56.76 \\
\hline Abdominal distention & 5 & 13.51 \\
\hline GIT symptoms & 2 & 5.41 \\
\hline Urinary symptoms & 4 & 10.81 \\
\hline Pelvic Heaviness & 1 & 2.70 \\
\hline Asymptomatic & 4 & 10.81 \\
\hline
\end{tabular}

Out of the 37 patients, 3 patients had only intra peritoneal adhesions in absence of any ovarian pathology and 2 patients had acute appendicitis. Rest 32 patients had an ovarian pathology (Table 7).

Table 7: Intraoperative findings.

\begin{tabular}{|lll|}
\hline Intra-op findings & $\begin{array}{l}\text { No. of } \\
\text { patients }\end{array}$ & $\begin{array}{l}\text { Percentage } \\
(\%)\end{array}$ \\
\hline Ovarian pathology & 32 & $84.49 \%$ \\
\hline Intra peritoneal adhesions & 3 & $8.11 \%$ \\
\hline Acute appendicitis & 2 & $5.40 \%$ \\
\hline
\end{tabular}


The most common pathology in these patients was a simple ovarian cyst $(45.95 \%)$, followed by endometriotic cyst $(21.62 \%)$, mucinous adenoma $(8.10 \%)$, serous cyst adenoma $(5.40 \%)$, serous cyst adenocarcinoma $(2.70 \%)$ and poorly differentiated adenocarcinoma (2.70\%) (Table 8).

Table 8: Histopathological reports of ovaries.

\begin{tabular}{|lll|}
\hline Histopathology & $\begin{array}{l}\text { No. of } \\
\text { patients }\end{array}$ & Percentage (\%) \\
\hline Simple ovarian cyst & 17 & 45.95 \\
\hline Endometriotic cyst & 8 & 21.62 \\
\hline Muscinous adenoma & 3 & 8.10 \\
\hline Serous cyst adenoma & 2 & 5.40 \\
\hline $\begin{array}{l}\text { Serous cyst } \\
\text { adenocarcinoma }\end{array}$ & 1 & 2.70 \\
\hline $\begin{array}{l}\text { Poorly differentiated } \\
\text { adeno carcinoma }\end{array}$ & 1 & 2.70 \\
\hline
\end{tabular}

\section{DISCUSSION}

Generally hysterectomy is regarded by females as end of gynecological problems but emergence of a pelvic mass subsequently has profound physical and psychological impact. ${ }^{3-5}$ Our preliminary study has looked into various possibilities along with its management.

Abdominal hysterectomy is still the commonest approach even if pre-requisite for vaginal approach are fulfilled. Multiple indications of operation in our series were in accordance with world literature.

Pelvic masses can originate from conserved ovaries either single or both, ovarian remnants ${ }^{6}$, retained fallopian tubes, broad ligament, retroperitoneal structures and other pelvic viscera. Ovarian carcinoma is regarded as a silent killer and rank number one in mortalities caused by gynecological cancers. Cancers can originate from ovarian remnants as well. ${ }^{7}$

Oophorectomy after menopause is a standard procedure with hysterectomy but it is technically more difficult with vaginal hysterectomy. Common practice is to leave healthy ovaries behind if vaginal hysterectomy is performed in postmenopausal women for prolapse, as facilities for laparoscopic assisted vaginal hysterectomy are very limited even in teaching hospitals. This practice should be discouraged. Pelvic masses have wide spectrum of imaging characteristics and clinical manifestations. Ultrasonography (either abdominal or vaginal), doppler is important in diagnosis, in monitoring and determining malignant potential and is costeffective.$^{8-10} \mathrm{CT}$ scan and MRI can also be considered as useful adjuvants.
In our study 11 women were managed conservatively with simple unilocular cyst with complete resolution in 612 month, though they were not included in the present study. At laparotomy ovarian tumors were excised. In suspected malignancy staging and de- bulking were carried out. After histopathology report, malignant cases were referred to oncology department. Two patients sustained small bowel injury during dissection of pelvic masses, which were repaired interoperatively with no sequel.

\section{CONCLUSIONS}

Emergence of pelvic mass after hysterectomy poses diagnostic and therapeutic challenge to gynecologists. Review of operation notes are of immense help regarding indications of surgery, ovarian conservation or removal and the state of pelvic structures. What then should be offered to a woman undergoing hysterectomy for a benign disease? Oophorectomy should be encouraged with hysterectomy after menopause. The benefits should be clearly explained and estrogen replacement offered to these women. Operative intervention after hysterectomy needs careful dissection with bowel preparation, as adhesions are common in such cases.

In future, as the patients become more aware and the clinicians more enlightened on the long term benefits and risks of hormone replacement therapy, decisions might be easier for the patients and the clinicians alike.

Funding: No funding sources

Competing interests: There are no competing interests to declare

Ethical approval: The study was approved by the Institutional ethics committee

\section{REFERENCES}

1. Healthcare Cost and Utilization Project (HCUP), 1988-2001: A Federal-State-Industry Partnership in Health Data. Rockville, Md: Agency for Healthcare Research and Quality; July 2003.

2. Farquhar CM, Sadler L, Harvey SA, Stewart AW. The association of hysterectomy and menopause: a prospective cohort study. BJOG 2005;112:956-62.

3. Naz F, Begum A. Experience with pelvic mass following hysterectomy for benign diseases. Biomedica 2004;20:106-9.

4. Khaw KT, Walker WJ. Ultrasound guided fine needle aspiration of ovarian cyst. Diagnosis and treatment in pregnant and non-pregnant women. Clin Radiol 1990;41:105-8.

5. Sheth SS. Vaginal Hysterectomy In: John Studd Progress in obstetrics and gynaecology. Vol 10 London: Churchill Livingstone 1993;317-39.

6. Krige CF. Vaginal hysterectomy and genital prolapse repair. A contribution to vaginal approach to operative gynaecology. Johannesburg. WitwaterStand University Press 1965. 
7. Dereska NH, Comella J, Hibner M, Magina JF. Mucinous adenocarcinoma in an ovarian remnant. Int J Gynecol Cancer 2004;14:683-6.

8. Fleisher AC, Tait D, Mayo J. Sonographic features of ovarian remnants. J Ultrasound Med 1998;17:551-5.
9. Chiang G, Levine D. Imaging of adnexal masses in pregnancy. J Ultrasound Med 2004;23:805-19.

10. Farina GP, Baccoli A, Pani C. Retroperitoneal Sarcomas: our experience. G Chir 2004;25:163-6.

DOI: $10.5455 / 2320-1770$. ijrcog20130202

Cite this article as: Bhatnagar P, Desai E, Patel U, Leuva B. Delayed re-laparotomy after total hysterectomy. Int J Reprod Contracept Obstet Gynecol 2013;2:12-5. 